\title{
Geleias de melão com casca e enriquecida com sementes de mandacaru
}

\section{Melon jellies in shell and enriched with mandacaru seeds}

\author{
Carolaine Gomes dos Reis ${ }^{1}{ }^{1}$; Rossana Maria Feitosa de Figueirêdo ${ }^{2}$; Alexandre José de Melo \\ Queiroz ${ }^{3}{ }^{3}$; Lumara Tatiely Santos Amadeu ${ }^{4}$; Thalis Leandro Bezerra de Lima ${ }^{5}$; Patrícia da Silva \\ Costa ${ }^{6}$
}

\begin{abstract}
${ }^{1}$ Mestranda em Engenharia Agrícola, Universidade Federal de Campina Grande, Campina Grande, Paraíba, carolainetecalimentos@gmail.com; ${ }^{2}$ Professora no Centro de Tecnologia e Recursos Naturais, Universidade Federal de Campina Grande, Campina Grande, Paraíba, rossanamff@gmail.com; ${ }^{3}$ Professor no Centro de Tecnologia e Recursos Naturais, Universidade Federal de Campina Grande, Campina Grande, Paraíba, alexandrejmq@ gmail.com; ${ }^{4}$ Mestranda em Engenharia Agrícola, Universidade Federal de Campina Grande, Campina Grande, Paraíba, lumaratatiely1993@gmail.com; ${ }^{5}$ Mestrando em Engenharia Agrícola, Universidade Federal de Campina Grande, Campina Grande, Paraíba, thallisma@gmail.com; ${ }^{6}$ Doutoranda em Engenharia Agrícola, Universidade Federal de Campina Grande, Campina Grande, Paraíba, patriciagroambiental@ gmail.com.
\end{abstract}

\section{A R T I G O}

Recebido: 02/03/2020

Aprovado: 26/09/2020

\section{Palavras-chave}

Processamento

Compostos bioativos

Aproveitamento integral

Co-produtos

Keywords

Processing

Bioactive compounds

Full use

Co-products

\section{R E S U M O}

A elaboração de geleias com a adição de resíduos do processamento de frutas, como cascas e sementes, pode proporcionar a redução de impactos ambientais e o enriquecimento nutricional dos produtos. Com vistas ao aproveitamento dos resíduos do processamento do melão e do mandacaru, assim como minimizar as perdas pós-colheita dessas frutas, objetivou-se a elaboração e caracterização de três formulações de geleias de melão cv. 'Orange Flesh', acrescidas da casca do melão e de sementes de mandacaru. As geleias foram caracterizadas quanto aos parâmetros físico-químicos $(\mathrm{pH}$, acidez total titulável, açúcares totais, açúcares redutores e não redutores, sólidos solúveis totais, teor de água, atividade de água e cinzas) e compostos bioativos (ácido ascórbico, compostos fenólicos totais, antocianinas totais e flavonoides totais). Das geleias elaboradas observou-se que a formulação com adição das cascas do melão cozidas (F3), foi a que obteve os maiores teores dos compostos bioativos, como os compostos fenólicos 39,98 mg 100 $\mathrm{g}^{-1}$, contudo as formulações F2 (geleia de melão com 1\% de sementes de mandacaru) e F1 (geleia de melão) obtiveram bons resultados. A polpa de melão, suas cascas e as sementes de mandacaru mostraram-se como alternativas viáveis na produção de geleias. A incorporação das sementes de mandacaru e das cascas do melão contribuiu para a funcionalidade e atratividade das geleias e serve como alternativa de aproveitamento de resíduos.

\section{A B S T R A C T}

The production of jams with the addition of residues from fruit processing, such as peels and seeds, can reduce environmental impacts and nutritionally enrich the products. With a view to using the residues from the melon and mandacaru processing, as well as minimizing the postharvest losses of these fruits, the objective was to develop and characterize three formulations of cv. 'Orange Flesh', plus melon peel and mandacaru seeds. The jellies were characterized according to the physical-chemical parameters $(\mathrm{pH}$, total titratable acidity, total sugars, reducing and non-reducing sugars, total soluble solids, water content, water and ash activity) and bioactive compounds (ascorbic acid, total phenolic compounds, total anthocyanins and total flavonoids). From the elaborated jellies it was observed that the formulation with the addition of the cooked melon peels (F3), was the one that obtained the highest levels of bioactive compounds, such as phenolic compounds $39.98 \mathrm{mg} 100^{-1} \mathrm{~g}^{-1}$, however the formulations F2 (melon jelly with $1 \%$ mandacaru seeds) and F1 (melon jelly) obtained good results. The melon pulp, its peels and mandacaru seeds proved to be viable alternatives in the production of jams. The incorporation of mandacaru seeds and melon peels contributed to the functionality and attractiveness of the jellies and serves as an alternative for using waste.

\author{
Revista Verde \\ ISSN 1981-8203 \\ Pombal, Paraíba, Brasil
}

v. 15, n.4, out.-dez., p.414-421, 2020 doi: $10.18378 /$ rvads.v15i4.7715 


\section{INTRODUÇÃO}

O melão (Cucumis melo L.) é dentre as cucurbitáceas, a mais cultivada no Brasil (540.229 t), exportando em 2018 197,60 mil toneladas de frutos frescos, recebendo destaque para a região Nordeste com os maiores produtores, os estados do Rio Grande do Norte (338.665 t) e Ceará (70.593 t), correspondendo juntos a mais de $75 \%$ da produção nacional (ANUÁRIO BRASILEIRO DE HORTI E FRUTI, 2018). A grande produção dessa região deve-se às condições climáticas que beneficiam o cultivo com altas temperaturas, baixa precipitação e elevada exposição solar (OLIVEIRA et al., 2019). O melão cv. 'Orange Flesh' possui grande potencialidade de produção, fazendo parte do grupo dos inodoros, tem formato arredondado, casca lisa de cor amarela a esbranquiçada, com polpa de cor alaranjada e de sabor doce (FIGUEIRÊDO et al., 2017).

Assim como a maioria das frutas, tem curta vida útil, devido principalmente ao seu alto teor de água, o que induz a perdas nas etapas de transporte, armazenamento e comercialização. Diante dessas características, existe a necessidade de se desenvolver produtos e processos que proporcionem a minimização dessas perdas (BESSA et al., 2018). A sua utilização na elaboração de produtos alimentícios, bem como a utilização dos resíduos gerados no processamento (sementes e cascas), são uma alternativa para redução dos impactos ambientais ocasionados pelo descarte da matéria orgânica, bem como uma possibilidade de diversificação de produtos no mercado (ALVES et al., 2019).

Dessa forma, a produção de geleias apresenta-se como uma boa alternativa, pois atua na redução do desperdício, devido à utilização de frutas consideradas inadequadas para venda na forma in natura (SOUZA et al., 2019). A denominação geleia é atribuída ao produto preparado à base de suco de fruta, utilizando ingredientes na quantidade adequada, os quais proporcionam um produto final na forma de gel, ocasionada pelo equilíbrio entre pectina, acidez e açúcar (SANTOS; OLIVEIRA, 2015). Segundo Storckl et al. (2013) a incorporação de cascas e sementes de melão em geleias mostraram-se promissoras, principalmente quanto a fibras, proteínas e polifenóis. A utilização de tais partes em produtos alimentícios justifica-se pelo valor nutricional e baixo teor calórico, além do reaproveitamento de resíduos.

O mandacaru (Cereus jamacaru) é uma espécie habitualmente encontrada na região Nordeste do Brasil, bastante resistente às condições climáticas, como os períodos de estiagem (DANTAS; OLIVEIRA, 2019). O fruto possui epicarpo avermelhado, polpa comestível de coloração branca e com inúmeras sementes pretas, que apesar de insípidas são comestíveis (ORTIZ; URBANO; TAKAHASHI, 2019; SANTOS NETO et al., 2019), além desementes ricas em carboidratos, com alto teor de proteínas, lipídeos, fibras e minerais (BAHIA et al., 2010; SILVA et al., 2019), o que ampara sua utilização em formulações de produtos alimentícios.

Com vistas ao aproveitamento dos resíduos do processamento do melão e do mandacaru, assim como minimizar as perdas pós-colheita dessas frutas, objetivou-se a elaboração e caracterização de três formulações de geleias de melão cv. 'Orange Flesh', acrescidas da casca do melão e de sementes de mandacaru.

\section{MATERIAL E MÉTODOS}

A pesquisa foi realizada no Laboratório de Armazenamento e Processamento de Produtos Agrícolas (LAPPA), da Unidade Acadêmica de Engenharia Agrícola, no Centro de Tecnologia e Recursos Naturais (CTRN) da Universidade Federal de Campina Grande (UFCG), campus Sede.

Os melões da variedade 'Orange Flesh' foram adquiridos no comércio local de Campina Grande - PB, sendo os mesmos provenientes de cultivo em Mossoró - RN e os mandacarus foram colhidos no município de Campina Grande, onde ambos foram selecionados pelo grau de maturação uniforme, tomando como critério a coloração da casca.

Após a aquisição dos frutos, os mesmos foram transportados para o laboratório, sendo sanitizadas com solução de hipoclorito de sódio a $200 \mathrm{ppm}$ por $15 \mathrm{~min}$ (para os melões) e 5 min (para os mandacarus), sendo posteriormente cortados em pedaços para facilitar a separação da polpa, sementes e cascas. Em seguida, a polpa foi homogeneizada em liquidificador doméstico e peneirada para refinamento da polpa. As cascas também foram trituradas em liquidificador doméstico com a finalidade de reduzir o tamanho das partículas e em seguida cozidas no vapor por 30 minutos com a finalidade de amaciamento. As sementes do mandacaru foram separadas da polpa através de peneiramento e lavagem em água corrente.

Para a elaboração das formulações utilizou-se a metodologia de Krolow (2005) com adaptações. As geleias produzidas foram do tipo extra que se caracteriza por ter 50 partes de polpa e 50 partes de açúcar $(50: 50 \mathrm{~m} / \mathrm{m})$. Foram elaboradas três formulações com concentração dos ingredientes constantes, como apresentado na Tabela 1 e codificadas de: (F1) geleia de melão; (F2) geleia de melão com sementes de mandacaru; e (F3) geleia de melão com suas cascas cozidas.

Tabela 1. Ingredientes e suas concentrações utilizadas na elaboração de geleias de melão 'Orange Fresh' tipo extra.

\begin{tabular}{lccc}
\hline \multirow{2}{*}{\multicolumn{1}{c}{ Ingredientes }} & \multicolumn{3}{c}{ Concentração (\%) } \\
\cline { 2 - 4 } & $\mathrm{F} 1$ & $\mathrm{~F} 2$ & $\mathrm{~F} 3$ \\
\hline Polpa de melão refinada & 50 & 50 & 50 \\
Açúcar cristal & 50 & 50 & 50 \\
\hline Pectina & 0,5 & 0,5 & 0,5 \\
Ácido cítrico & 0,760 & 0,654 & 0,713 \\
Água & 20 & 20 & 20 \\
Cascas de melão cozida & - & - & 10 \\
Sementes de mandacaru & - & 1 & - \\
\hline
\end{tabular}

Inicialmente pesou-se separadamente o equivalente a $50 \%$ da polpa e $50 \%$ do açúcar, em seguida, a partir da massa total destes dois ingredientes, pesou-se a massa equivalente a $0,5 \%$ de pectina, $20 \%$ de água, $10 \%$ de cascas de melão cozidas e $1 \%$ sementes de mandacaru (Tabela 1). A concentração do ácido cítrico foi dependente da correção do $\mathrm{pH}$, uma vez que a mistura do sistema fruta, pectina e açúcar não foi capaz de 
suavisar o pH da amostra, a adição do acidulante faz-se necessária, visto que é necessário níveis baixos de $\mathrm{pH}$ para assim obter a geleificação adequada, bem como realçar o sabor da fruta, além de também possuir papel importante na conservação (RIBEIRO et al., 2016).

Para o preparo da geleia $\mathrm{F} 1$, inicialmente adicionou-se à polpa de melão refinada, $1 / 2$ do açúcar pesado e a água, homogeneizando-se até completa diluição. Fez-se então a medida do $\mathrm{pH}$ da mistura e corrigiu-se com ácido cítrico para a faixa de 3,25-3,36.

Posteriormente a mistura seguiu para cocção em panela de aço inoxidável, em chapa elétrica sob constante agitação, até atingir temperatura de $65-70{ }^{\circ} \mathrm{C}$, onde imediatamente adicionou-se lentamente a pectina misturada com um pouco de açúcar, com a finalidade de não aglomerar a mistura, a qual permaneceu sob cocção por 3 a 4 min adicionando-se em seguida o restante do açúcar. $O$ processo de cozimento prosseguiu até a geleia atingir o teor de sólidos solúveis na faixa de 65 a $70{ }^{\circ}$ Brix.

Após a cocção as formulações foram envasadas em potes de vidro esterilizados e as embalagens invertidas por $5 \mathrm{~min}$ para completa esterilização e vedação das tampas. As geleias embaladas foram resfriadas em temperatura ambiente $\mathrm{e}$ armazenadas sob refrigeração a $5{ }^{\circ} \mathrm{C}$ (UR 80-90\%) até realização das análises.

Para a elaboração das formulações F2 (com casca cozida) e F3 (com sementes de mandacaru) seguiu-se o mesmo procedimento (F1), adicionando-se as cascas e as sementes no início, juntamente com a polpa refinada e parte do açúcar.

A polpa de melão refinada e as geleias elaboradas foram analisadas, em triplicata, quanto os seguintes parâmetros físicoquímicos: $\mathrm{pH}$; teor de água; sólidos totais; cinzas; acidez total titulável; e teor de sólidos solúveis totais $\left({ }^{\circ} \mathrm{Brix}\right)$, determinadas de acordo com as metodologias do Instituto Adolfo Lutz (IAL, 2008). Açúcares redutores, açúcares não redutores e açúcares totais segundo Lane-Eynon (1923). A atividade de água $\left(\mathrm{a}_{\mathrm{w}}\right)$ foi determinada por leitura direta na amostra a $25^{\circ} \mathrm{C}$ em analisador de atividade de água (Aqualab - modelo 3TE - Decagon).

$\mathrm{O}$ teor de ácido ascórbico foi determinado pela metodologia da AOAC (1997) modificada por Benassi e Antunes (1998) a qual se baseia na redução do 2,6 diclorofenolindofenol-sódio (DCFI) pelo ácido ascórbico, utilizando o ácido oxálico como solução extratora. Para a determinação dos compostos fenólicos totais utilizou-se a metodologia descrita por Waterhouse (2006) e para determinação de flavonoides e antocianinas utilizou-se metodologia de Francis (1982).

O delineamento adotado foi o inteiramente casualizado (DIC) com três repetições e na análise estatística. Empregou-se à análise de variância (ANOVA), observando a significância do teste $\mathrm{F}$ e para a comparação entre médias usou-se o teste de Tukey a $5 \%$ de probabilidade $(\mathrm{p}<0,05)$, através do programa computacional Assistat ${ }^{\circledR}$ versão 7.7 (SILVA; AZEVEDO, 2016).

\section{RESULTADOS E DISCUSSÃO}

Os parâmetros avaliados na caracterização físico-química e compostos bioativos da polpa de melão cv. 'Orange Flesh' refinada, encontram-se dispostos na Tabela 2, com suas respectivas médias e desvios padrão.

$\mathrm{O}$ produto apresentou elevado teor de água, atividade de água, baixa acidez $(\mathrm{pH})$ e acidez total titulável, demonstrando assim ser um produto altamente perecível, propício ao desenvolvimento de micro-organismos, indicando ser necessária a adoção de algum tipo de procedimento de conservação para o ampliação da vida útil (FRANCO; LANDGRAF, 2005).

Tabela 2. Caracterização físico-química e compostos bioativos da polpa de melão cv. 'Orange Flesh' refinada.

\begin{tabular}{|c|c|}
\hline Parâmetros & $\begin{array}{c}\text { Média e } \\
\text { desvio padrão }\end{array}$ \\
\hline Teor de água (\%) & $91,62 \pm 0,06$ \\
\hline Sólidos totais (\%) & $8,38 \pm 0,06$ \\
\hline Atividade de água $\left(\mathrm{a}_{\mathrm{w}}\right)$ a $25{ }^{\circ} \mathrm{C}$ & $0,993 \pm 0,000$ \\
\hline Cinzas (\%) & $0,50 \pm 0,01$ \\
\hline $\mathrm{pH}$ & $6,20 \pm 0,01$ \\
\hline Acidez total titulável - ATT (\% ácido cítrico) & $0,06 \pm 0,002$ \\
\hline Sólidos Solúveis Totais - SST $\left({ }^{\circ}\right.$ Brix $)$ & $7,00 \pm 0,00$ \\
\hline Relação SST/ATT & $116,67 \pm 0,30$ \\
\hline ais (\% glicose) & $5,98 \pm 0,06$ \\
\hline Açúcares redutores (\% glicose) & $4,16 \pm 0,00$ \\
\hline Açúcares não redutores (\% sacarose) & $1,74 \pm 0,06$ \\
\hline Ácido ascórbico $\left(\mathrm{mg} 100^{-1} \mathrm{~g}^{-1}\right)$ & $0,35 \pm 0,01$ \\
\hline Compostos fenólicos totais (mg EAG. $100^{-1} \mathrm{~g}^{-1}$ ) & $29,16 \pm 010$ \\
\hline Flavonoides $\left(\mathrm{mg} 100^{-1} \mathrm{~g}^{-1}\right)$ & $1,10 \pm 0,01$ \\
\hline Antocianinas $\left(\mathrm{mg} 100^{-1} \mathrm{~g}^{-1}\right)$ & $0,12 \pm 0,01$ \\
\hline
\end{tabular}

EAG - equivalente ácido gálico

O teor de água e de cinzas da polpa de melão foram semelhantes aos valores reportados na Tabela Brasileira de Composição de Alimentos (TACO, 2011), que menciona teores de $91,3 \%$ e $0,5 \%$, respectivamente. O alto teor de água implica na perecibilidade do produto assim como observado por Antunes et al. (2017) e por Bramont et al. (2018) ao analisarem polpas de frutas. O teor de cinzas detectado é um indicativo de que como a maioria das frutas, o melão é pobre em minerais, assim como observado por Lima et al. (2015) para 15 amostras de polpas de frutas valores que variaram entre 0,19 a $0,60 \%$ de cinzas.

A alta atividade de água detectada na polpa refinada $(0,993)$ implica na facilidade de deterioração do produto, demandando a utilização de processos que proporcionem a sua conservação. Comumente, são determinadas elevadas atividades de água nas polpas de frutas $(>0,95)$, como na polpa de araticum $(0,98)$ (MORAIS et al., 2017) e de cupuaçu $(0,99)$ (DIAS et al., 2019).

De acordo com o $\mathrm{pH}$, a polpa de melão é classificada como um alimento pouco ácido $(\mathrm{pH}>4,5)$ diferente da maioria das frutas que são classificadas como alimentos ácidos $(\mathrm{pH}$ entre 4,0-4,5) (FRANCO; LANDGRAF, 2005). Valores próximos para esse parâmetro foram reportados por Dalastra et al. (2016) para os melões Amarelo (6,43) e Pele de Sapo $(6,49)$, confirmando que é uma característica desta fruta. Por outro lado, apresentaram-se superiores aos reportados por Carmo et al. (2017) para cinco variedades de melões (Valenciano Amarelo, Pele de Sapo Juazeiro, Cantaloupe Harper, Ashira 
Amarelo e Gália Néctar) os quais, em média, obtiveram pH de 5,30 .

A acidez total titulável da polpa de melão $(0,06 \%$ ácido cítrico) obteve valor inferior quando comparada a mesma espécie de melão e outras como o amarelo e o rendilhado, os quais variaram entre 0,17 a 0,24\% (DALASTRA et al., 2016), além do meloeiro amarelo híbrido Gradial, o qual apresentou $0,19 \%$ (PINTO et al., 2019). Por outro lado, valores semelhantes foram reportados por Bellon et al. (2015) com 0,079\% no melão-andino.

O teor dos sólidos solúveis totais $\left(7^{\circ}\right.$ Brix $)$ da polpa de melão apresentou-se inferior ao valor padrão para as exportações de melão in natura que dependendo do cultivar varia de 9-13 ${ }^{\circ}$ Brix (PINTO et al., 2019). Apesar disso, Guimarães et al. (2020) obtiveram valores de sólidos solúveis totais inferiores (4,5-5,0 ${ }^{\circ}$ Brix) para o melão Sunrise utilizando diferentes tipos de adubação.

A relação SST/ATT $(116,67)$ revela quimicamente que o melão está no estágio de maturação maduro, com sabor adocicado (FACHINELLO et al., 2008). Valor superior desta relação foi detectado por Santos et al. (2019) para polpa de melão congelada $(\mathrm{SST} / \mathrm{ATT}=125)$, ressaltando que durante o amadurecimento das frutas os ácidos orgânicos são degradados pelo aumento da concentração das enzimas, reduzindo o sabor ácido e aumentando o valor da relação SST/ATT (COSTA et al., 2017).

Foram detectados teores de açúcares totais de 5,98\% glicose, encontrando-se a predominância dos redutores $(4,16 \%$ glicose) em relação aos não redutores (1,74\% sacarose). Valores superiores foram observados por Santos e Carvalho (2016) para os AR da polpa de melão coroá $(9,04 \%)$, por Santos et al. (2019) para os AT da polpa congelada de melão $(10,78 \%)$ e por Véras et al. (2019) em melões gália cv. Solarnet com teores médios durante o armazenamento de $8,1 \%$ (atmosfera normal) e 8,3\% (atmosfera modificada). Estas diferenças podem estar relacionadas ao estádio de maturação dos frutos, variedade e condições de processamento e armazenamento.

Observa-se um teor de ácido ascórbico de $0,35 \mathrm{mg} 100^{-1} \mathrm{~g}$ ${ }^{1}$, estando abaixo do encontrado na polpa de melão caroá concentrada $\left(1,76 \mathrm{mg} 100^{-1} \mathrm{~g}^{-1}\right)$ analisada por Jesus e seus colaboradores (2016), bem como para outras frutas como umbu (3,36 a 5,47 mg $100^{-1} \mathrm{~g}^{-1}$ ) (BASTOS et al., 2016) e da polpa de abacaxi com hortelã (1,20 mg $\left.100^{-1} \mathrm{~g}^{-1}\right)$ (LIMA et al., 2015). Assim observa-se que vários fatores podem influenciar $\mathrm{o}$ parâmetro como o armazenamento, diferentes variedades de frutas, propriedades, genética, entre outras variáveis.

$\mathrm{O}$ teor dos compostos fenólicos totais $(29,16 \mathrm{mg}$ EAG $100^{-1} \mathrm{~g}^{-1}$ ) foi superior ao valor reportado por Brito (2017) para a polpa do melão Orange $\left(22,6 \mathrm{mg}\right.$ EAG $\left.100^{-1} \mathrm{~g}^{-1}\right)$. O teor de flavonoides e antocianinas detectados $\left(1,10\right.$ e $0,12 \mathrm{mg} 100^{-1} \mathrm{~g}^{-1}$, respectivamente) foram próximos ao reportado por Oliveira (2013) para o melão Orange $\left(1,27 \mathrm{mg} 100^{-1} \mathrm{~g}^{-1}\right.$ e $0,15 \mathrm{mg} 100^{-1}$ $\left.\mathrm{g}^{-1}\right)$. Esses valores são importantes nos alimentos, pois esses compostos bioativos influenciam nas propriedades nutricionais e sensoriais, além de atuarem como antioxidantes, reduzindo os radicais livres, o que consequentemente auxilia na redução de riscos de doenças cardíacas (ABREU et al., 2019; GUIMARÃES et al., 2020).

Dos resultados apresentados dos parâmetros físicoquímicos e compostos bioativos da polpa de melão observa-se que as divergências com relação aos valores da literatura, que podem ter ocorrido em decorrência das diferenças no estádio de maturação, tipo de processamento, variedade, condições edafoclimáticas de cultivo, colheita, transporte, entre outros fatores (MARO et al., 2013).

Na Tabela 3 estão dispostos as médias e os desvios padrão dos parâmetros analisados para as geleias elaboradas. Observase que as formulações não diferiram estatisticamente quanto ao teor de água e sólidos totais, sendo assim, as sementes de mandacaru e as cascas do melão não foram capazes de influenciar em tais parâmetros.

Em relação ao teor de água, valores próximos aos do presente trabalho foram reportados por Miguel et al (2008) para a geleia de melão 'Amarelo' elaborada com resíduo de polpa, $(29,78 \%)$ e dentro da faixa determinada por Maldonado et al. (2019) em várias geleias produzidas a partir de frutas e resíduos, com teores variando entre 12 e $46 \%$.

Tabela 3. Caracterização físico-química e compostos bioativos de formulações de geleias de melão cv 'Orange Flesh'.

\begin{tabular}{|c|c|c|c|}
\hline Parâmetros & F1 & $\mathrm{F} 2$ & F3 \\
\hline Teor de água $(\%)$ & $25,79 \pm 1,11^{\mathrm{a}}$ & $25,37 \pm 0,11^{\mathrm{a}}$ & $26,91 \pm 0,80^{\mathrm{a}}$ \\
\hline Sólidos totais (\%) & $74,21 \pm 1,11^{\mathrm{a}}$ & $74,63 \pm 0,11^{\mathrm{a}}$ & $73,09 \pm 0,80^{\mathrm{a}}$ \\
\hline Atividade de água $\left(\mathrm{a}_{\mathrm{w}}\right)$ a $25^{\circ} \mathrm{C}$ & $0,791 \pm 0,001^{\mathrm{c}}$ & $0,833 \pm 0,001^{\mathrm{a}}$ & $0,813 \pm 0,00^{\mathrm{b}}$ \\
\hline Cinzas $(\%)$ & $0,340 \pm 0,01^{b}$ & $0,360 \pm 0,01^{\mathrm{ab}}$ & $0,363 \pm 0,01^{\mathrm{a}}$ \\
\hline $\mathrm{pH}$ & $2,96 \pm 0,01^{\mathrm{c}}$ & $3,09 \pm 0,01^{\mathrm{b}}$ & $3,12 \pm 0,00^{\mathrm{a}}$ \\
\hline Acidez total titulável (\% ácido cítrico) & $1,00 \pm 0,00^{\mathrm{a}}$ & $0,85 \pm 0,02^{\mathrm{c}}$ & $0,90 \pm 0,002^{b}$ \\
\hline Açúcares totais (\% glicose) & $60,61 \pm 0,00^{\mathrm{a}}$ & $59,18 \pm 0,39^{b}$ & $51,86 \pm 0,30^{\mathrm{c}}$ \\
\hline Açúcares redutores (\% glicose) & $32,54 \pm 0,37^{\mathrm{a}}$ & $15,43 \pm 0,18^{\mathrm{c}}$ & $25,04 \pm 0,27^{\mathrm{b}}$ \\
\hline Açúcares não redutores (\% sacarose) & $26,67 \pm 0,35^{b}$ & $41,56 \pm 0,32^{\mathrm{a}}$ & $25,07 \pm 0,53^{c}$ \\
\hline Compostos fenólicos (mg. $\left.100^{-1} \mathrm{~g}^{-1}\right)$ & $29,06 \pm 0,15^{\mathrm{c}}$ & $29,55 \pm 0,04^{b}$ & $39,98 \pm 0,11^{\mathrm{a}}$ \\
\hline Flavonoides $\left(\mathrm{mg} \cdot 100^{-1} \mathrm{~g}^{-1}\right)$ & $1,17 \pm 0,01^{\mathrm{b}}$ & $1,08 \pm 0,02^{\mathrm{c}}$ & $1,57 \pm 0,01^{\mathrm{a}}$ \\
\hline Antocianinas (mg.100-1 $\left.\mathrm{g}^{-1}\right)$ & $0,09 \pm 0,00^{b}$ & $0,07 \pm 0,00^{\mathrm{c}}$ & $0,16 \pm 0,01^{\mathrm{a}}$ \\
\hline
\end{tabular}

F1 - geleia de melão; F2 - geleia de melão + 1\% sementes de mandacaru; F3 - geleia de melão + $10 \%$ cascas de melão.

Médias seguidas pela mesma letra na mesma linha não diferem estatisticamente entre si ao nível de 5\% de probabilidade pelo teste de Tukey. 
A atividade de água $\left(\mathrm{a}_{\mathrm{w}}\right)$ foi estatisticamente superior nas formulações F2 $(0,833)$ e F3 $(0,813)$ em relação a F1 $(0,791)$, portanto, diferentemente do teor de água, este parâmetro foi influenciado pela adição das sementes de mandacaru e das cascas do melão, revelando que as formulações F2 e F3 possuem maior quantidade de água livre para ser utilizada em reações, seja elas, químicas, enzimáticas ou microbiológicas (PICANÇO et al. 2018). A formulação $F 1$ apresentou $a_{w}$ próxima à geleia de umbu-cajá $(0,774)$ (OLIVEIRA et al., 2014), todas as formulações obtiveram comportamento semelhante as geleias elaboradas com a polpa do melão pele de sapo para F1 - (polpa: açúcar (1:1)), F2 - (F1 + 0,6\% sementes de maracujá) e F3 (F1 + 10\% cascas de melão) (AMADEU et al., 2020).

Quanto aos sólidos solúveis totais (SST) a F1 diferiu estatisticamente das demais, ao nível de 5\% de probabilidade, apresentando o maior valor, estando próximo aos obtidos nas geleias de acerola (66,92 a 67,97 ${ }^{\circ}$ Brix) (CAETANO et al., 2012). As formulações F2 e F3 apresentaram valores de SST próximos aos reportados por Barros et al. (2020) para a geleia de morango com pimenta $\left(64,66^{\circ}\right.$ Brix $)$ e próximas a geleia de melão pele de sapo $(65,00$ a 67,83) (AMADEU et al., 2020). Estas diferenças provavelmente devem-se aos altos teores de sólidos insolúveis e/ou fibras que as sementes e cascas utilizadas possuem, reduzindo desta forma o teor de SST das formulações, conforme valores de fibra alimentar relatado por Mallek-Ayadi et al. (2017) para farinha das cascas de melão cv. Maazoun $(41,69 \%)$ e por Vieira et al. (2017) para a farinha das cascas de melão amarelo $(34,62 \%)$.

$\mathrm{O}$ teor de cinzas das geleias variou entre 0,340 e $0,363 \%$, com a F3 apresentando a maior concentração, diferindo significativamente $(p>0,05)$ em relação a $F 1$, decorrente dos minerais contidos na casca. Baixos teores de cinzas, também foram reportados por Moura et al. (2019) (0,30 a 0,35\%) em geleias de maracujá com sementes de linhaça marrom, por Lemos et al. (2019) $(0,63$ a $0,76 \%)$ nas geleias prebióticas mistas de jabuticaba e acerola, além de Barros et al. (2019) $(0,25$ a $0,46 \%)$ em geleias de abacaxi e canela com diferentes tipos de açúcar.

Quanto ao $\mathrm{pH}$, as amostras diferiram estatisticamente entre si, variando entre 2,96 e 3,12, sendo consideradas como muito ácidas ( $\mathrm{pH}<4,0)$ (FRANCO; LANDGRAF, 2005). A F1 apresentou o menor $\mathrm{pH}$, seguido de $\mathrm{F} 2$ e $\mathrm{F} 3$, revelando que a correção do $\mathrm{pH}$ com o ácido cítrico pode ter sido influenciado pelas sementes e cascas. Verifica-se que as geleias com esses valores de $\mathrm{pH}$ implicam em alto poder de conservação, proporcionada pela limitação de desenvolvimento de microorganismos nesta faixa (FRANCO; LANDGRAF, 2005). Resultados próximos foram obtidos por Silva et al. (2012) em geleias de cambuci $(3,02-3,10)$, por Paiva et al. (2015) em geleia de melão $(3,07)$ e por Mattos et al. (2018) $(3,19$ e 3,35) para geleia de amora-preta com pimenta e geleia de amorapreta, respectivamente. Por outro lado, valores inferiores foram verificados em geleias mistas de umbu e mangaba com $\mathrm{pH}$ entre 2,30-2,63 (SOUZA et al., 2018).

As médias da acidez total titulável dos produtos diferiram estatisticamente entre si, observando-se que a acidez reduziu com adição das cascas (F3) e sementes (F2) em relação à padrão (F1). A discrepância apresentada entre a ATT da polpa de melão refinada quando comparada com as geleias pode ser explicada pela adição do ácido cítrico durante a elaboração das mesmas. Valores inferiores foram reportados por Curi et al. (2017) em geleias de pêssegos $\left(0,19\right.$ a $\left.0,52 \mathrm{~g}_{100^{-1}} \mathrm{~g}^{-1}\right)$ e superiores encontrados por Teles et al. (2017) em geleias tipo extra de graviola com adição de pimenta dedo-de-moça, obtendo ATT de 1,65\% ácido cítrico.

Os teores de ácido ascórbico foram baixos, o que era esperado, visto que a matéria-prima utilizada também era detentora de baixo teor $\left(0,35 \mathrm{mg} 100^{-1} \mathrm{~g}^{-1}\right)$. Apesar disso, observa-se que todas as formulações obtiveram concentrações maiores que a apresentada para polpa utilizada, o que revela que as etapas de elaboração das geleias concentraram o ácido ascórbico, além da adição de outros ingredientes. A geleia elaborada com adição da casca do melão (F3) esteve com maior concentração, seguida das geleias $\mathrm{F} 1$ e $\mathrm{F} 2$, as quais não apresentaram diferença significativa entre as médias.

Quanto aos açúcares redutores, não redutores e totais, houve diferença estatística entre as formulações, onde a F1 apresentou maior percentual de açúcares totais (AT) e redutores (AR), o que pode ser justificado em razão de conter apenas a polpa refinada do melão, que tem em sua composição a predominância dos AR. A F2 obteve os maiores percentuais dos açúcares não redutores, influenciada pela semente de mandacaru. Viana et al. (2012) reportaram teores de açúcares totais próximos em geleias de mamão com araçá-boi com diferentes proporções $(52,76$ a $58,73 \%)$, assim como para as geleias de amora-preta com teores entre 59,54-61,85\% (SOUZA et al., 2015), próxima as formulações F1 e F2.

A formulação com adição da casca do melão (F3) obteve maiores concentrações dos compostos fenólicos totais $(39,98 \mathrm{~g}$

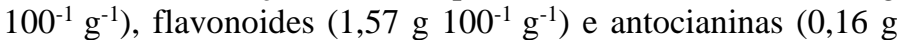
$100^{-1} \mathrm{~g}^{-1}$ ) quando comparada com as demais e com a polpa refinada, revelando que a incorporação da casca proporcionou o aumento dos compostos bioativos. A geleia com adição das sementes de mandacaru (F2) apresentou-se com resultados superiores a formulação padrão, o que demonstra que as sementes são ricas em compostos fenólicos, que foram incorporados à geleia.

\section{CONCLUSÕES}

A polpa de melão cv. 'Orange Flesh', as suas cascas e as sementes de mandacaru são boas alternativas na produção de geleias, visto que todas as formulações apresentaram características satisfatórios, como conservação, atribuída as características físico-químicas ( $\mathrm{pH}$, teor de água, atividade de água), e compostos bioativos. Os resíduos utilizados contribuem para a funcionalidade das formulações, mediante os valores dos compostos bioativos e servem como alternativa para a inserção de novos produtos no mercado alimentício.

\section{REFERÊNCIAS}

ABREU, B. B.; MARINHO, A. R. S.; PASSOS, J. C.; SOUSA, C. R. N.; BRANDÃO, A. C. A. S.; OLIVEIRA, M. L. V. S. ARAÚJO, R. S. R. Composição centesimal, compostos bioativos e atividade antioxidante em cálice de hibisco 
(Hibiscus sabdariffa L.). Jornal Interdisciplinar de Biociências, v. 4, n. 1, p. 1-4, 2019.

ALVES, G. S.; SILVA, C. E. P.; ALVES, K. M. C.; ARAÚJO, E. C. N.; ALVES, J. E. A.; ARAGÃO, C. S. B.; MARQUES, L. F. Processamento de suco concentrado adicionado de farinha de semente de melão amarelo. Revista Semiárido De Visu, v. 7, n. 1, p. 3-14, 2019.

AMADEU, L. T. S.; FIGUEIRÊDO, R. M. F.; QUEIROZ, A. J. M.; REIS, C. G.; LIMA, T. L. B.; COSTA, P. S. Resíduos de frutas na elaboração de geleia de melão Pele de Sapo. Revista Verde, v. 15, n. 2, p. 153-159, 2020. 10.18378/rvads.v15i2.7716

ANUARIO. Anuário Brasileiro da Fruticultura 2019. Santa Cruz do Sul: Editora Gazeta, 2018. 96p.

ANTUNES, B. F.; SALDANHA, E. S.; KRUMREICH, F. D.; LORINI, A.; CARDOSO, M. C.; OTERO, D. M.; ZAMBIAZI, R. C. Qualidade de frutas nativas do Brasil. Revista da Jornada de Pós-Graduação e Pesquisa-Congrega Urcamp, p. 2367-2379, 2017.

ASSOCIATION OF OFFICIAL ANALYTICAL CHEMISTS. Methods of analysis. 16th ed. Gaitherburg: AOAC, 1997.

BAHIA, E. V. A.; MORAIS, L. R. V.; SILVA, M. P.; LIMA, O. B. V.; SANTOS, S. F. Estudo das características físicoquímicas do fruto do mandacaru (Cereus jamacaru P.DC.) cultivado no sertão pernambucano. In: CONGRESSO DE PESQUISA E INOVAÇÃO DA REDE NORTE-NORDESTE DE EDUCAÇÃO TECNOLÓGICA, 5., 2010, Maceió. Anais... Maceió: IFAL, 2010.

BARROS, S. L.; SANTOS, N. C.; MELO, M. O. P.; NASCIMENTO, A. P. S.; SOUSA, F. M.; SANTOS, R. M. S.; FIGUEIRÊDO, D. V. P. Qualidade físico-química e textural de geleias elaborados com morango, pimenta e maltodextrina. Research, Society and Development, v. 9, n.1, p. 1-19, 2020.

BARROS, S. L.; SILVA, W. P.; FIGUEIRÊDO, R. M. F.; ARAÚJO, T. J.; SANTOS, N. C.; GOMES, J. P. Efeito da adição de diferentes tipos de açúcar sobre a qualidade físicoquímica de geleias elaboradas com abacaxi e canela. Revista Principia, n. 45, p. 150-157, 2019.

BAStOS, J. S.; MARTINEZ, E. A.; SOUZA, S. M. A. Características físico-químicas da polpa de umbu (Spondias tuberosa Arruda Câmara) comercial: efeito da concentração. Journal of Bioenergy and Food Science, v. 3, n. 1, p. 11-16, 2016.

BELlON, A. A.; GUIMARÃES, L. A. O. P.; SOUZA, J. L.; FAVARATO, L. F.; DIAS, M. A.; BALBINO, J. M. S. Características pós-colheita de melão-andino em função do tempo de armazenamento. In: ENCONTRO LATINOAMERICANO DE INICIAÇÃO CIENTÍFICA, 19; ENCONTRO LATINO AMERICANO DE PÓS GRADUAÇÃO, 15.; ENCONTRO LATINO AMERICANO DE INICIAÇÃO CIENTIFÍCA JÚNIOR, 9.; ENCONTRO NACIONAL DE INICIAÇÃO À DOCÊNCIA, 5., 2015, São
José dos Campos. Anais... São José dos Campos: UNIVAP, 2015.

BENASSI, M. T.; ANTUNES, A. J. A. Comparison of metaphosphoric and oxalic acids as extractant solutions for thedetermination of vitamin $\mathrm{c}$ in selected vegetables. Arquivosde Biologia e Tecnologia, v. 31, n. 4, p. 507-513, 1998.

BESSA, M. A. D.; OLIVEIRA, E. N. A.; FEITOSA, B. F.; FEITOSA, R. M.; ALMEIDA, F. L. C.; OLIVEIRA NETO, J. O. Bebida alcoólica fermentada de melão (Cucumis melo L.): processamento e caracterização. Brazilian Journal Food Technological, v. 21, p. 1-5, 2018. 10.1590/1981-6723.21717

BRAMONT, W. B.; LEAL, I. L.; UMSZA-GUEZ, M. A.; GUEDES, A. S.; ALVES, S. C. O.; REIS, J. H. O.; BARBOSA, J. D. V.; MACHADO, B. A. S. Comparação da composição centesimal, mineral e fitoquímica de polpas e cascas de dez diferentes frutas. Revista Virtual de Química, v. 10, n. 4, p. 811$823,2018$.

BRITO, E. S. Avaliação da capacidade antioxidante de variedades de melão (Cucumis melo L.) comercializadas no Brasil e determinação do teor de glutationa reduzida (GSH). 2017. 130 f. Tese (Doutorado em Ciências de Alimentos) Universidade Estadual de Campinas, Campinas, 2017.

CAETANO, P. K.; DAIUTO, E. R.; VIEITES, R. L. Característica físico-química e sensorial de geleia elaborada com polpa e suco de acerola. Brazilian Journal of Food Technology, v. 15, n. 3, p. 191-197, 2012. 10.1590/S1981$\underline{67232012005000011}$

CARMO, I. L. G. S.; FERREIRA, R. S.; SOUZA, J. T. A.; FIGUEIREDO, L. F.; MEDEIROS, R. D. Produção e qualidade de cultivares de melão em Savana de Boa Vista, Roraima. Revista Agropecuária Técnica, v. 38, n. 2, p. 78-83, 2017. $\underline{10.25066 / \text { agrotec.v38i2.28212 }}$

COSTA, J. D. S.; FIGUEIREDO NETO, A.; ALMEIDA, F. A. C.; COSTA, M. S.; BORGES, G. S. C.; SOUSA, K. S. M.; QUIRINO, A. K. R. Componentes principais de parâmetros físico-químicos de mangas cv. 'Tommy Atkins' durante a maturação. Espacios, v. 38, n. 16, p. 1-11, 2017.

CURI, P. N.; TAVARES, B. S.; TADEU, M. H.; MELO, E. T.; PIO, R.; SOUZA, V. R. Peach cultivars from tropical regions: characterization and processing potential. Ciência Rural, v. 47, n. $12,2017.10 .1590 / 0103-8478 \mathrm{cr} 20170293$

DANTAS, J. I. M.; OLIVEIRA, M. G. B. Versatilidade no uso medicinal de mandacaru (Cereus jamacaru) Cactaceae. Diversitas Journal, v. 4, n. 2, p.384-392, 2019. 10.17648/diversitas-journal-v4i2.737

DALASTRA, G. M.; ECHER, M. M.; KLOSOWSKI, E. S.; HACHMANN, T. L. Produção e qualidade de três tipos de melão, variando o número de frutos por planta. Revista Ceres, v. $63, \quad$ n. 4 , p. 427-450, 2016. 10.1590/0034737X201663040013 
DIAS, J. D. M.; ABREU, V. K. G.; PEREIRA, A. L. F.; LEMOS, T. O.; SANTOS, L. H.; SILVA, V. K. L.; MOTA, A. S. B. Desenvolvimento e avaliação das características físicoquímicas e da aceitação sensorial de doce em massa de cupuaçu. Boletim do Centro de Pesquisa de Processamento de Alimentos, v. 36, n. 1, p. 1-10, 2019.

FACHINELlO, J. C.; NACHTIGAL，J. C.; KERSTEN, E. Colheita e armazenamento. In: Fruticultura fundamentos e práticas. Pelotas, 2008.

FIGUEIRÊDO, M. C. B.; GONDIM, R. S.; ARAGÃO, F. A. S. Produção de melão e mudanças climáticas: sistemas conservacionistas de cultivo para redução das pegadas de carbono e hídrica. Brasília: Embrapa, 2017. 302 p.

FRANCIS, F. J. Analysis of anthocyanins. In: MARKAKIS, P. Anthocyanins as food colors. New York: Academic Press, 1982. p. 181-207.

FRANCO, B. D. G. M; LANDGRAF, M. Microbiologia de alimentos. São Paulo: Atheneu, 2005.

GUIMARÃES, B. R.; ARAÚJO, A. R. R; PACHECO, M. J. B.; SOUZA, F. J. L.; CARDOSO, A. T. A.; ALMEIDA G. V. Caracterização e produção dos frutos de meloeiro (Cucumis melo L.) influenciados por adubação. Revista Ibero Americana de Ciências Ambientais, v. 11, n. 1, p. 289-299, 2020. $\underline{\text { 10.6008/CBPC2179-6858.2020.001.0026 }}$

GUIMARÃES, K. C.; SALGADO, D. L.; CARVALHO, E. E. $\mathrm{N}$. Evaluation of different methodologies for the determination of phenolic compounds in tropical fruits. Brazilian Journal of Food Technology, v. 23, p.1-7, 2020. 10.1590/19816723.01519

INSTITUTO ADOLFO LUTZ. Métodos físico-químicos para análise de alimentos. 4. ed. São Paulo: Instituto Adolfo Lutz, 2008. 1020 p.

JESUS, G. F.; BASTOS, J. S.; OLIVEIRA, N. A.; ANJOS, M. B.; SANTOS, J. C. R.; SOUZA, S. M. A.; MARTINEZ, E. A. Estudos preliminares na formulação de estruturados de mix de polpa de frutas. Revista do Congresso Sul Brasileiro de Engenharia de Alimentos, v. 2, n. 1, p. 1-10, 2016.

KROLOW, A. C. R. Preparo artesanal de geleias e geleiadas. Pelotas: Embrapa Clima Temperado, 2005. 29 p. (Embrapa Clima Temperado. Documentos, 138).

LANE, H.; EYNON, L. Determination of reducing sugar by means of Fehling's solution with methylene blue as internal indicador. Journal of the Society of Chemistry Industry, v. 42, p. 32T-37T, 1923.

LEMOS, D. M.; ROCHA, A. P. T.; GOUVEIA, J. P. G.; OLIVEIRA, E. N. A.; SOUSA, E. P.; SILVA, S. F. Elaboração e caracterização de geleia prebiótica mista de jabuticaba e acerola. Brazilian Journal Food Technology, v. 22, p. 1-13, 2019. 10.1590/1981-6723.09818

LIMA, T. L. S.; CAVALCANTE, C. L.; SOUSA, D. G.; SILVA, P. H. A.; ANDRADE SOBRINHO, L. G. Avaliação da composição físico-química de polpas de frutas comercializadas em cinco cidades do Alto Sertão paraibano. Revista Verde, v. 10, n. 2, p. 49 - 55, 2015.

MALDONADO, R. R.; GOMES, T. S. N.; EMILIANO, A.; TIEMI, J.; SILVA, N. A.; SOUZA, A. K.; CARAM, A. L. A.; OLIVEIRA, D. S. Aproveitamento integral de frutas para produção de geleias. In: BARBOSA, F. C. Nutrição em foco: uma abordagem holística. Piracanjuba: Editora Conhecimento Livre, 2019. p. 144-162.

MALLEK-AYADI, S.; BAHLOUL, N.; KECHAOU, N. Characterization, phenolic compounds and functional properties of Cucumis melo L. peels. Food Chemistry, v. 221, p. 1691$1697,2017$.

MARO, L. A. C; PIO, R.; GUEDES, M. N. S.; ABREU, C. M. P.; CURI, P. N. Bioactive compounds, antioxidant activity and mineral composition of fruits of raspberry cultivars grown in subtropical areas in Brazil. Fruits, v. 68, n. 3, p. 209-217, 2013. $\underline{10.1051 / \text { fruits/2013068 }}$

MATTOS, M. G.; OLIVEIRA, B. A. S.; RAMM, A.; MACIEJEWSKI, P.; ASSIS, A. M.; SCHUCH, M. W. Avaliação química, colorimétrica e sensorial de geleias de amora-preta comercializadas na região sul. Revista da Jornada da Pós-Graduação e Pesquisa - Congrega, v. 15, n. 15, p. 801$809,2018$.

MIGUEL, A. C. A.; ALBERTINI, S.; BEGIATO, G. F.; DIAS, J. R. P. S.; SPOTO, M. H. F. Aproveitamento agroindustrial de resíduos sólidos provenientes do melão minimamente processado. Ciência e Tecnologia de Alimentos, v. 28, n. 3, p. 733-737, 2008.

MOURA, H. V.; SILVA, E. T. V.; FIGUEIRÊDO, R. M. F.; MOREIRA, I. S.; QUEIROZ, A. J. M. Produção e caracterização de geleias de maracujá com sementes de linhaça marrom. Revista Brasileira de Higiene e Sanidade Animal, v. 13, n. 2, p. 218-229, 2019.

MORAIS, E. C.; PATIAS, S. G. O.; FERREIRA, N. S. S.; PICANÇO, N. F. M.; RODRIGUES, E. C.; NASCIMENTO, E.; FARIAS, R. A. P. G. Compostos bioativos e características físico-químicas de polpa de araticum in natura e pasteurizada. Brazilian Journal of Food Technology, v. 20, p. 1-9, 2017. $\underline{10.1590 / 1981-6723.14216}$

OLIVEIRA, E. N. A.; SANTOS, D. C.; ROCHA, A. P. T.; GOMES, J. P. Desenvolvimento, caracterização e estabilidade de geleia tradicional de umbu-cajá. Revista Brasileira de Fruticultura, v. 36, n. 3, p. 640- 651, 2014.

OLIVEIRA, K. J. A. Compostos bioativos e capacidade antioxidante em melões comercializados na Paraíba. 2013. 86 f. Trabalho de Conclusão de Curso (Bacharelado em Engenharia de Alimentos) - Centro de Ciências e Tecnologia Agroalimentar, Universidade Federal de Campina Grande, Pombal, 2013.

OLIVEIRA, L. A. A.; CARDOSO, E. A.; RICARTE, A. O.; MARTINS, A. F.; COSTA, J. M.; NUNES, G. H. S. Stability, adaptability and shelf life of Cantaloupe melon hybrids. Revista 
Brasileira de Fruticultura, v. 41, n. 5, e-418, 2019. $\underline{10.1590 / 0100-29452019418}$

ORTIZ, T. A.; URBANO, M. R.; TAKAHASHI, L. S. A. Effects of water deficit and $\mathrm{pH}$ on seed germination and seedling development in Cereus jamacaru. Semina: Ciências Agrárias, v. 40, n. 4, p. 1379-1392, 2019. 10.5433/16790359.2019v40n4p1379

PAIVA, C. A.; AROUCHA, E. M. M.; FERREIRA, R. M. A.; ARAÚJO, N. O.; SILVA, P. S. L. Alterações físico-químicas de geleias de melão e acerola durante o armazenamento. Revista Verde, v. 10, n. 3, p 18-23, 2015. 10.18378/rvads.v10i3.3495

PICANÇO, Y. S.; OLIVEIRA, S. S.; ALMEIDA, M.; OTANI, F. S.; PEREIRA, E. J.; SANTOS, G. C. Análise de atividade de água e umidade na qualidade do mel produzido em comunidades da reserva extrativista Tapajós - Arapiuns, Santarém, Pará. Agroecossistemas, v. 10, n. 2, p. 1-10, 2018.

PINTO, J. M.; YURI, J. E.; CALGARO, M.; CORREIA, R. C. Consumo hídrico de melão irrigado por gotejamento cultivado em fileiras simples e dupla. In: INOVAGRI INTERNATIONAL MEETING, 5.; CONGRESSO NACIONAL DE IRRIGAÇÃO E DRENAGEM, 28.; SIMPÓSIO LATINO AMERICANO DE SALINIDADE, 1., 2019, Fortaleza. Anais... Fortaleza: Instituto de Pesquisa e Inovação na Agricultura Irrigada, UFC, ABID, 2019.

RIBEIRO, L. M. P.; DAMASCENO, K. A.; GONÇALVES, R. M. S.; GONÇALVES, C. A. A.; ALVES, A. N.; CUNHA, M. F. Acidez, sua relação com $\mathrm{pH}$ e qualidade de geleias e doces em barra. Boletim Técnico IFTM, v. 2, n. 2, p. 14-19, 2016.

SANTOS, B. A.; TEIXEIRA, F.; AMARAL, L. A.; RANDOLPHO, G. A.; SCHWARZ, K.; SANTOS, E. F.; RESENDE, J. T. V.; NOVELLO, D. Caracterização química e nutricional de polpa de frutas armazenadas sob congelamento. Revista da Universidade Vale do Rio Verde, v. 17, n. 1, p. 1-13, 2019.

SANTOS, D. C.; OLIVEIRA, E. N. A. Tecnologia de frutas e hortaliças. Natal: IFRN, 2015. 234 p.

SANTOS, F. S.; CARVALHO, G. B. M. Elaboração de uma cerveja tipo ale utilizando melão coroá (Sicana odorífera (Vell.). Naudin) como adjunto do malte. Anais Seminário de Iniciação Científica, n. 20, 2016. 10.13102/semic.v0i20.3115

SANTOS NETO, J. P.; SILVA, V. D. N.; SILVA, P. A.; SANTOS, Y. M. P.; MONTEIRO, P. H. S.; SILVA, L. A. S. G. Características físico-químicas de frutos de mandacaru (Cereus jamacaru P. DC.) cultivados no sertão alagoano. Revista Craibeiras de Agroecologia, v. 4, n. 1, e 7741, 2019.

SILVA, F. A. S.; AZEVEDO, C. A. V. The Assistat software version 7.7 and its use in the analysis of experimental data. African Journal of Agricultural Research, v. 11, n. 39, p. 3733 3740, 2016. 10.5897/AJAR2016.11522

SILVA, I. G.; CORREIA, A. F. K.; BIGARAN, J. T.; BAPTISTA, C. P.; CARMO, L. F.; APOTO, M. H. F. Estudo de caracterização do fruto cambuci [Campomanesia phaea (O.
Berg.) Landrum] e sua aplicação no processamento de geleia. Boletim do Centro de Pesquisa de Processamento de Alimentos, v. 30, n. 1, p. 83-90, 2012.

SILVA, S. N.; SILVA, P. B.; SILVA, R. M.; SILVA, L. P. F. R.; BARROSO, A. J. R.; ALMEIDA, F. A. C.; GOMES, J. P. Composição físico-química e colorimétrica da polpa de frutos verdes e maduros de Cereus jamacaru. Magistra, v. 30, p. 11$17,2019$.

STORCKL, C. R.; NUNES, G. L.; OLIVEIRA, B. B.; BASSO, C. Folhas, talos, cascas e sementes de vegetais: composição nutricional, aproveitamento na alimentação e análise sensorial de preparações. Ciência Rural, v. 43, n. 3, p. 537-543, 2013. $\underline{10.1590 / \mathrm{S} 0103-84782013000300027}$

SOUZA, A. V.; RODRIGUES, R. J.; GOMES, E. P.; GOMES, G. P.; VIEITES, R. L. Caracterização bromatológica de frutos e geleias de amora-preta. Revista Brasileira de Fruticultura, v. 37, n. 1, p. 013-019, 2015. 10.1590/0100-2945-037/14

SOUZA, H. R. S.; CARVALHO, M. G.; SANTOS, A. M.; FERREIRA, I. M.; SILVA, A. M. O. Compostos bioativos e estabilidade de geleia mista de umbu (Spondias tuberosa Arr. C.) e mangaba (Hancornia speciosa G.). Revista Brasileira de Higiene e Sanidade Animal, v. 12, n. 2, p. 236-248, 2018.

SOUZA, R. S.; CUELLAR, J. P.; DONADON, J. R.; GUIMARÃES, R. C. A. Compostos bioativos em geleia de bocaiuva com maracujá. Multitemas, v. 24, n. 57, p. 79-94, 2019. 10.20435/multi.v0i.1803

TACO - TABELA BRASILEIRA DE COMPOSIÇÃO DE ALIMENTOS. 4. ed. rev. e ampl. Campinas: NEPAUNICAMP, 2011. $161 \mathrm{p}$.

TELES, A. C. M.; PINTO, E. G.; SANTOS, J. R.; OLIVEIRA, C. F. D.; SOARES, D. S. B. Desenvolvimento e caracterização físico-química de geleia comum e extra de graviola com pimenta. Revista de Agricultura Neotropical, v. 4, n. 1, p. $72-$ 77, 2017. 10.32404/rean.v4i1.1341

VÉRAS, M. L. M.; ARAÚJO, F. F.; GOMES JUNIOR, J.; FINGER, F. L. Enzymatic activity and post-harvest quality of 'Galia' melon under storage temperatures and modified atmosphere. Revista Brasileira de Ciências Agrarias, v. 14, n. 1, p. 1-6, 2019. 10.5039/agraria.v14i1a5617

VIANA, E. S.; JESUS, J. L.; REIS, R. C.; FONSECA, M. D.; SACRAMENTO, C. K. Caracterização físico-química e sensorial de geleia de mamão com araçá-boi. Revista Brasileira de Fruticultura, v. 34, n. 4, p. 1154-1164, 2012. 10.1590/S010029452012000400024

VIEIRA, R. F. F. A.; CARVALHO, C. L. S.; CARVALHO, I. R. A.; CANDIDO, C. J.; SANTOS, E. F.; NOVELlO, D. Adição de farinha da casca de melão em cupcakes altera a composição físico-química e a aceitabilidade entre crianças. Conexão Ci., v. 12, n. 2, p. 22-30, 2017.

WATERHOUSE, A. Folin-ciocalteau micro method for total phenol in wine. American Journal of Enology and Viticulture, p. 3-5, 2006. 